\title{
Experimental investigation to the desalination performance of a system due to integration of a solar collection chamber and a cooling chimney
}

\author{
Qichao Hu, Xiaoxin Wang and Peiwen Li \\ Department of Aerospace and Mechanical Engineering \\ The University of Arizona \\ Tucson, AZ 85721
}

\begin{abstract}
The paper presents a concept and experimental study to a solar thermal desalination system, which has three components integrated, including a glass-covered solar thermal collection chamber, a basin with salty water for evaporation, and a cooling chimney for water vapor condensation. Both clean water and salts can be collected as products for maximized value and leaving no waste discharge and minimal impact to the environment. An experimental system was constructed for laboratory test before outdoor on-sun operation. Constant temperature of the water in water basin was maintained by electrical heaters in the experimental test. Measurements were conducted for airflow rate drawn into the solar collection chamber, and the humidity and temperature of the humid air at locations of in and outlet of the cooling chimney. Understanding to the relationship of water temperatures and airflow rate as well as water production rate has been obtained, which will lead to optimization design of the system for better energy efficiency.
\end{abstract}

Key words: Zero waste discharge, desalination, solar thermal energy, cooling chimney, heat/mass transfer.

\section{Introduction}

With the growth of world population and climate change, lack of clean water becomes a major issue that has been discussed around the world for many years ${ }^{[1]}$. Fortunately, it is typical that most arid areas in the world are accompanied by an abundance of solar energy. Therefore, using solar energy to produce clean water through desalination of seawater or recycle of used/damaged water can dramatically reduce the energy cost for clean water production $^{[2-5]}$.

Solar energy can be harvested and converted into thermal energy or electrical energy for different purpose of energy utilization. The energy conversion efficiency from solar energy to electrical energy is still not sufficiently high and the cost is also expensive either using solar PV or using concentrated solar power technology. However, converting solar energy into thermal energy with a high efficiency is relatively easy to accomplish at low cost. Therefore, directly using solar thermal energy for water treatment has a great advantage.

Currently, desalination technologies can be classified into two categories. The first one is based on membrane techniques. Due to osmosis process, water molecules can pass through the membrane, while salts in the seawater cannot, which thus separates water and salts ${ }^{[6-10]}$. A majority of seawater desalination stations are based on reverse osmosis technology. The other category is thermal driven distillation, which relies on thermal energy to evaporate water, after which the water vapor is condensed for obtaining clean water. Multi-stage flashing and multi-effect distillation are two very popular technologies relying on thermal energy for desalination ${ }^{[11-15]}$.

Considering the relatively low cost of converting solar energy into thermal energy, using solar thermal energy and thermal driven water distillation is of interest to the current study. For even lower cost of solar thermal energy collection, the proposed technology in this study does not employ solar concentration, but simply traps solar energy through greenhouse effect ${ }^{[16]}$ and the obtained thermal energy is then used for water evaporation.

Figure 1 illustrates the concept of solar collection and seawater desalination in a glass-covered water basin. A thin layer of seawater in the water basin is in the glass-covered space, where water evaporates due to the heating from the captured heat from solar energy. The water vapor coming out from the seawater can rise and be ventilated through the cooling chimney. The chimney is externally cooled by convective ambient air at a relatively lower temperature and 
also through radiative heat dissipation to the sky. The condensed water at the inner wall of the chimney flows down and is collected by water holders for clean water.

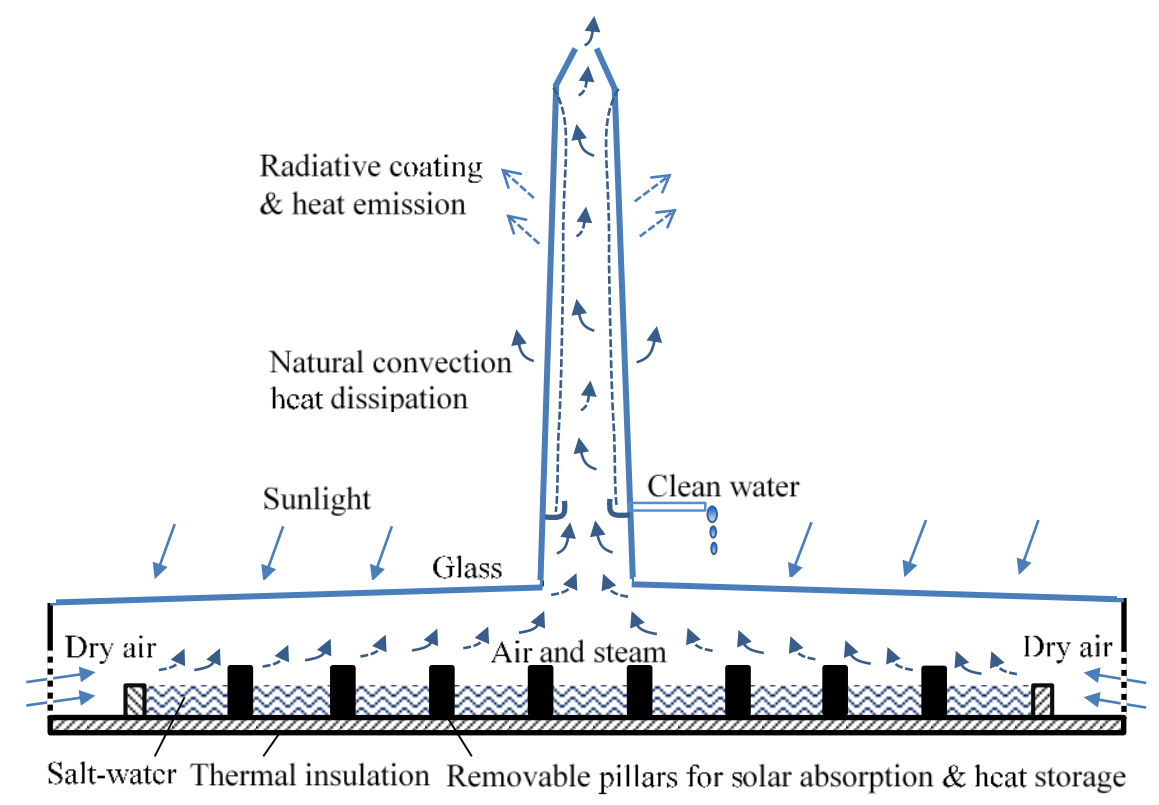

Fig. 1 Concept of glass-covered solar collection chamber and water basin integrated with cooling chimney for condensation of water vapor for clean water.

The physics involved in the above-described solar desalination system include greenhouse effect for solar energy collection, evaporation and condensation heat transfer in phase change processes of water, and flow due to buoyancy effect in the cooling chimney. The glass-covered space is designed to be a space that has black blocks at the bottom of the water basin, which can collect the heat from the sunlight that passes through the glass. The glass material allows the short wavelength, visible light to go into the space but stops the long wavelength thermal radiation from going out of the solar collection space. This is the greenhouse effect by which solar thermal energy is trapped. The heat absorbed by the black blocks and the black bottom of the water basin provides the energy to evaporate the water in the glasscovered space.

Around the shallow water basin, dry air can flow into the glass-covered space due to buoyancy force and the chimney effect. The airflow can carry away the water vapor at the water surface and flows up to the cooling chimney. During this process, mass transfer between water vapor and air occurs from the water surface to the bulk airflow in the solar collection chamber. The airflow velocity and flow rate are determined by the chimney effect. The higher the chimney is, the more airflow may occur, and thus more water vapor can be taken away. The chimney must be made to have a thermal conductive thin wall in order to better conduct the heat from the moisture-laden airflow to the ambient air outside of the chimney. At the outside wall of the chimney, natural convective heat transfer between the cooling chimney and ambient air occurs. In the meantime, radiative coating can be applied to the outer surface of the chimney to get more energy radiated to the sky, which has a lower temperature than the chimney surface ${ }^{[16]}$. While the heat transfer coefficient of evaporation and condensation is very effective, the heat transfer from the chimney to the ambient air can be the major thermal resistance that dominates the water collection rate; therefore, external fins at the outer surface of the chimney might also be adopted for heat transfer enhancement. The condensed water at the inner surface of the cooling chimney can flow down to a water holder. The entire system desalinates seawater relying on solar energy and natural phenomena of chimney effect and natural convective air cooling, with addition of radiative cooling. The land utilization for solar collection can reach 100 percent (compared to trough or heliostat solar concentrating technologies) and the system operation does not need electrical power to drive the flows, which thus results in very low cost for operation and maintenance. The next three sections present some basic analysis and experimental test results in a preliminary study. 


\section{Basic theoretical analysis}

A fundamental understanding to the maximum potential of water production rate is important to the overall merit evaluation of the technology. Two ideal situations are considered for analysis. The first case is based on an assumption that the system is fully enclosed and thus the energy trapped in the solar collection space drives the evaporation of the water. The water vapor rises to the cooling chimney through natural convection and condenses into liquid water. If the trapped thermal energy is predictable at the time with sunlight available, the generated clean water can be simply estimated through the computation of the energy:

$$
\begin{aligned}
& Q=\beta \cdot I_{\text {solar }} \cdot A \cdot \Delta t \\
& m_{H 2 O}=\frac{Q}{r}
\end{aligned}
$$

where $I_{\text {solar }}$ is the solar irradiance heat flux $\left(\mathrm{W} / \mathrm{m}^{2}\right), \beta$ is the percentage of the trapped net thermal energy compared to the energy of the sunlight on the solar collection area, $A$ is the area through which sunlight enters the energy collection space, $\Delta t$ is the time period of operation with sunlight, $r$ is the latent heat of water vaporization. From the point view of the natural convection of water vapor in the system, moisture will rise and go into the cooling chimney for condensation. Such an enclosed system behaves like a heat pipe except in the real operation, air as a none condensing gas, cannot be fully vacuumed from the system, and therefore, the evaporation and condensation heat transfer processes are negatively impacted.

In the second case of analysis, the system is open. It is assumed that dry air flows into the glass-covered solar collection space, and the heat and mass transfer between the air and the water fully humidifies the air for it to reach a humidity of 1.0. Due to the chimney effect, the hot humid air ventilate through the cooling chimney. It is assumed that the moist air is fully cooled in the cooling chimney and liquid water precipitates, so that the humidity of air reaches 1.0 at a lower temperature at the exit of the cooling chimney. Then, the water precipitation can be calculated based on the high and low temperatures, assuming the moist air is an ideal gas. The driving force for the flow through the chimney and the ideal amount of condensed water are analyzed in the following part.

The pressure of air at the solar collection space inlet is assumed as $1.0 \mathrm{~atm}$, which is due to the gravity of air,

$$
P_{\text {inlet }}=1.0 \mathrm{~atm}=\rho_{\text {dry-air }} g H_{\infty}
$$

where $\rho_{d r y \text {-air }}$ is the dry air density, $g$ is gravity, and $H_{\infty}$ is the thickness of air covering the earth.

At the outlet of the chimney, the pressure of air is calculated as:

$$
P_{\text {chimney-out }}=\rho_{\text {dry-air }} g\left(H_{\infty}-H_{\text {chimney }}\right)
$$

where $H_{\text {chimney }}$ is the height of the chimney.

The pressure at the inlet of the chimney will fully depends on the humidity of the air. Assume the density of the humid air is known as $\rho_{\text {moist-air }}$, the pressure at the inlet of the chimney is given as:

$$
P_{\text {chimney-in }}=\rho_{\text {dry-air }} g\left(H_{\infty}-H_{\text {chimney }}\right)+\rho_{\text {moist-air }} g H_{\text {chimney }}
$$

where the density of moist air inside the chimney is determined through the following equation, under the condition that the absolute humidity ratio $x=m_{\text {water }} / m_{\text {air }}$ in the humid air is available.

$$
\rho_{\text {moist-air }}=\rho_{\text {dry-air }}(1+x) /\left(1+x \frac{R_{\text {water }}}{R_{\text {air }}}\right)
$$


where $R_{\text {water }}$ and $R_{\text {air }}$ are the gas constant of water vapor and air, respectively; $x$ is the absolute humidity ratio. Since $R_{\text {water }}$ is greater than $R_{\text {air }}$, it is easy to find out that the density of dry air is greater than that of moist air.

Comparing the pressures in Eqs. (3), (4), and (5), we obtain the pressure differences that drive the flow in the chamber and in the cooling chimney.

$$
\begin{aligned}
& \Delta P_{\text {chamber }}=P_{\text {inlet }}-P_{\text {chimney-in }}=\left(\rho_{\text {dry-air }}-\rho_{\text {moist-air }}\right) g H_{\text {chimney }} \\
& \Delta P_{\text {chimney }}=P_{\text {chimney-in }}-P_{\text {chimney-out }}=\rho_{\text {moist-air }} g H_{\text {chimney }}
\end{aligned}
$$

This indicates that because of the chimney effect, dry air from ambient flows into the solar collection chamber, and after humidification moist air flows up into the cooling chimney. Although there is no temperature explicitly showing up in the Eqs. (7) and (8), temperature does affect the relative and absolute humidity of air (in the chamber and cooling chimney) and thus the density of the humid air.

Consider an ideal case that dry air can be fully humidified in the water basin to reach a humidity of 1.0. Furthermore, we also assume that the moisture is condensed so that at the exit of the chimney the humid air also reaches a humidity of 1.0 at a lower temperature due to the cooling. Therefore, the condensed water can be calculated theoretically through the following equation:

$$
\dot{m}=\left(\frac{P_{\text {bottom }}^{\text {sat }}}{T_{\text {bottom }}}-\frac{P_{\text {outlet }}^{\text {sat }}}{T_{\text {outlet }}}\right) \cdot \frac{1}{R_{\text {water }}}(\mathrm{kg} / \mathrm{s}) \text { if volume flow rate of air is } 1.0 \mathrm{~m}^{3} / \mathrm{s} \text {. }
$$

where the saturate pressures of steam corresponding to the temperatures at the bottom and top of the cooling chimney are used. The first part in Eq. (9) reflects the amount of water in the humid air (as given bellow) before it enters the cooling chimney, assuming $1.0 \mathrm{~m}^{3} / \mathrm{s}$ dry air is fully humidified in the water basin.

$$
\dot{m}_{\text {evaporation }}=P_{\text {bottom }}^{\text {sat }} /\left(T_{\text {bottom }} R_{\text {water }}\right)(\mathrm{kg} / \mathrm{s}) \text { if volume flow rate of air is } 1.0 \mathrm{~m}^{3} / \mathrm{s} \text {. }
$$

The system's actual desalination performance can be greatly affected by the solar collection and water vapor condensation, depending on how well the dry air can be humidified and how thoroughly the moist air is dehumidified. Inside the cooling chimney is where the condensation heat transfer of humid air occurs. With a higher chimney the air flow rate may increase and heat transfer rate also increases due to the area increase. Better heat dissipation at the outside of the chimney is also very important for the moisture in the humid air being condensed into water.

\section{Experimental setup and test procedures}

Outdoor experimental test with actual sunlight being harvested for water desalination will have a significant uncertainty due to the change of sunlight and the ambient air temperature. Because the solar collection, water evaporation temperature, and cold air temperature at outdoor operation can all vary with time in the day, it becomes difficult to find a distinct relationship of water collection rate with the evaporation temperature in the water basin, and the steam condensation temperature in the cooling chimney as well. In order to have temperature-controlled experimental tests and investigation, lab-scale test systems have been constructed. Instead of having sunlight collection for heating, blanket heaters were used to control the heating and the temperature in the water basin to be constant. Constant ambient air temperature is also maintained in air-conditioned lab, which allows the experimental tests to have controlled steady states.

Two different water basins made of 5052 Aluminum alloy were constructed for the tests, one has a basin area of $1 \mathrm{~m} \times 1 \mathrm{~m}$, and another has $2 \mathrm{~m} \times 2 \mathrm{~m}$. A 3D drawing of the system is shown in Fig. 2(a), and a photograph is given in Fig. 2(b) for the constructed system with water basin of $2 \mathrm{~m} \times 2 \mathrm{~m}$. On the four side walls of the water basin, there are holes in diameter of $3 \mathrm{~cm}$ open to room air. The $1 \mathrm{~m} \times 1 \mathrm{~m}$ basin has 10 holes on each side, and the $2 \mathrm{~m} \times 2 \mathrm{~m}$ basin has 18 holes on each side. Due to the chimney effect, dry air from the lab enters into the solar collection chamber through the holes and flows through the surface of the water in the basin. Since the water temperature is higher than the dry air, air is humidified before it is ventilated by the cooling chimney.

The same cooling chimney made of 6061 Aluminum alloy (as shown in Fig. 2(b)) was used for both of the basins. The chimney has a height of $3 \mathrm{~m}$, with inner and outer diameters of $0.254 \mathrm{~m}$ and $0.273 \mathrm{~m}$, respectively. 
Blanket heaters of the size of $1 \mathrm{~m} \times 1 \mathrm{~m}$ with $1 \mathrm{kw}$ power output and $2 \mathrm{~m} \times 2 \mathrm{~m}$ with $4 \mathrm{kw}$ power output were used respectively for the two different water basins. Underneath the blanket heater is a thermal insulation plate with a thickness of $25.4 \mathrm{~mm}$ and thermal conductivity of $0.0289 \mathrm{~W} /\left(\mathrm{m}{ }^{\circ} \mathrm{C}\right)$, which stops the heat from conducting to the concrete floor. Polycarbonate glass with a $4.5 \mathrm{~mm}$ thickness was used to cover the water basin. During all experiments, the distance from the water surface to the glass cover is kept at $5 \mathrm{~cm}$ by feeding water every 5 minutes with an accuracy of $\pm 0.2 \mathrm{~mm}$.

Structures for water collection in the cooling chimney, as illustrated in Fig. 1, was built in the real aluminum chimney at near the low end. The collected clean water by the chimney is introduced out to flow to a collection beaker for measuring the volume at a time interval.

The top of the chimney may fully open, or capped by cones as shown in Fig. 3. The cones have different opening area ratio compared to the full opening of the chimney, which helps control the flow rate of dry air entering to the system. The flow control is to avoid extreme case where too much airflow enters the water basin and unable to get fully humidified to reach a relative humidity of 1.0 in the water basin.

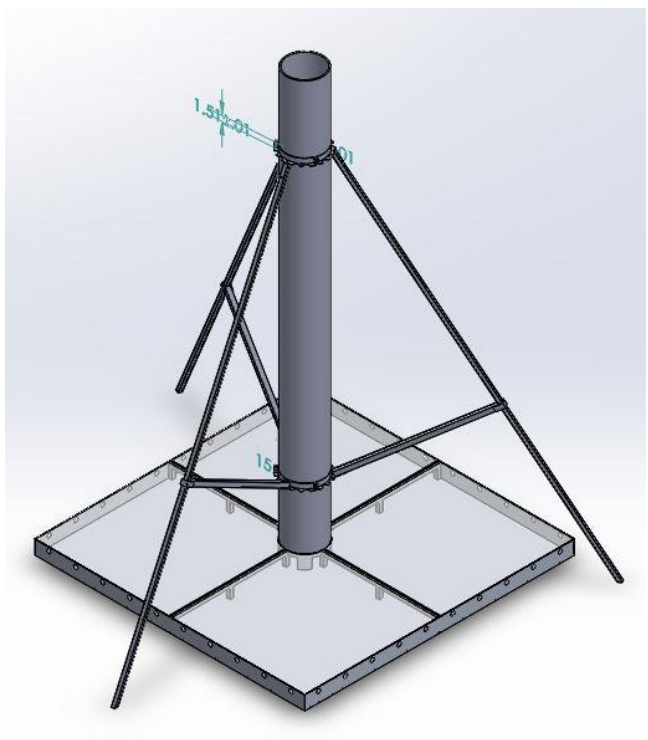

(a)

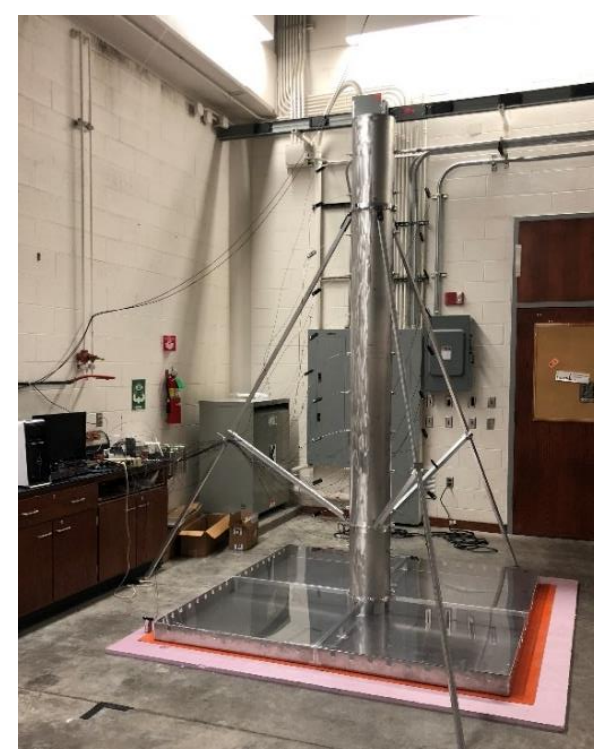

(b)

Fig. $23 D$ model of the system design and photograph of the actual installed test unit

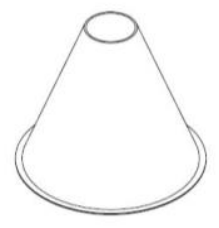

$9.0 \%$

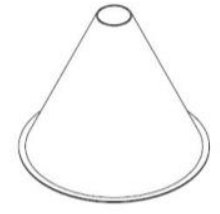

$4.0 \%$

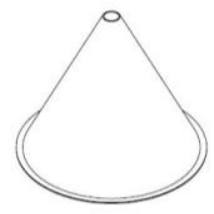

$1.0 \%$

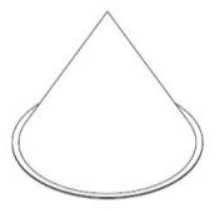

$0.0 \%$

Fig. 3 Cones with different opening area ratios against the base to cap the chimney for flow area control

Experimental tests have been carried out at several different water evaporation temperatures from $30^{\circ} \mathrm{C}$ to $60{ }^{\circ} \mathrm{C}$. The uncertainty of temperature control is $\pm 0.2^{\circ} \mathrm{C}$ based on the temperature measurement. During each test, the water evaporation temperature in the water basin is controlled constant. The maximum temperature of $60{ }^{\circ} \mathrm{C}$ was selected based on a proof test in a real outdoor on-sun experiment using a glass-covered black pan filled with a thin layer of water.

Parameters including the water evaporation temperature, the humidity and temperature of the humid air at the bottom and top of the chimney, the dry air velocity entering the holes on the side walls of the water basin, the temperatures of the inner and outer walls of the chimney are all monitored using data acquisition system. The uncertainty of temperature measurement is $0.2^{\circ} \mathrm{C}$, the accuracy of velocity is $\pm 0.015 \mathrm{~m} / \mathrm{s}$ and that of relative humidity is $0.01 \%$. 


\section{Results and discussions}

Both the theoretical analysis and experimental study are aimed at understanding the ideal situation of water collection by the system, as well as the effects of the water evaporation temperature and the cooling air temperature to the water collection. Experimental work will also help understand the relationship of the dimensions of the cooling chimney and water evaporation basin for maximized water collection and energy efficiency.

\subsection{Results about ideal water evaporation and condensation every $1.0 \mathrm{~m}^{3} / \mathrm{s}$ of airflow drawing into the system.}

Assume that there is $1.0 \mathrm{~m}^{3} / \mathrm{s}$ dry air drawn into the system by the chimney effect, we can then use Eqs. (9) and (10) to calculate both the water from condensation in the cooling chimney and the evaporated water going to the cooling chimney. Assume an ideal situation that the airflow is fully humidified, the evaporated water at different temperatures can be found as shown in Fig. 4 together with the correspondingly condensed water at $25^{\circ} \mathrm{C}$ and at 35 ${ }^{\circ} \mathrm{C}$, respectively. Here the ambient air temperature of $25^{\circ} \mathrm{C}$ and $35^{\circ} \mathrm{C}$ represent two typical temperatures of the local weather at Tucson Arizona, which is abundant of solar energy.

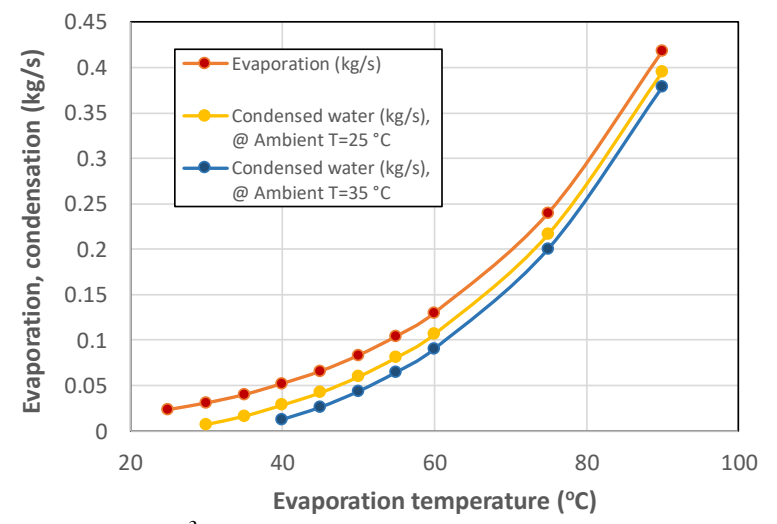

Fig. 4 Ideal situation that dry air of $1.0 \mathrm{~m}^{3} / \mathrm{s}$ is fully humidified in the water basin at different temperatures and is then fully dehumidified at temperature of $25^{\circ} \mathrm{C}$ and $35^{\circ} \mathrm{C}$ respectively in the cooling chimney.

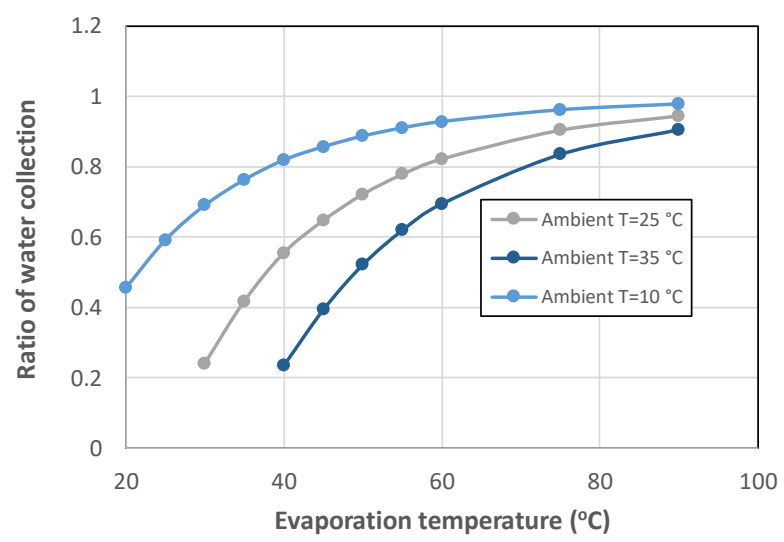

Fig. 5 Water collection ratio as a function of the evaporation temperature and cooling air temperature

When the condensed water is compared to that of the evaporated water, we can get the ratio of water harvest, which is given in Fig. 5. Obviously, if the ambient temperature for the cooling chimney is lower (for example at $10{ }^{\circ} \mathrm{C}$ ), the ratio of the harvested water versus the evaporated water can be much higher, compared to that of the case of a cooling temperature of $25^{\circ} \mathrm{C}$ and $35^{\circ} \mathrm{C}$. It is noted from Fig. 4 that the water evaporation rate increases faster than a linear case against the temperature of evaporation. However, the water collection ratio is largely determined by the cooling temperature, as shown in Fig. 5. If the cooling air temperature is as low as $10^{\circ} \mathrm{C}$, the water harvest ratio can reach $80 \%$ even if the vaporization temperature is $40^{\circ} \mathrm{C}$. This indicates that in wintertime, the water collection ratio can be sufficiently high due to the low ambient temperature, although the water production rate can be low due to the low temperature evaporation. 


\subsection{Experimental test results}

The water temperature in the water basin was heated by electrical heaters and controlled to be constant during experiment. At any constant water temperature, the temperatures of the humid air, the wall temperature of the inside and outside of the cooling chimney were recorded using a data acquisition system. The room temperature of the air is $23 \pm 0.2{ }^{\circ} \mathrm{C}$ during all the tests.
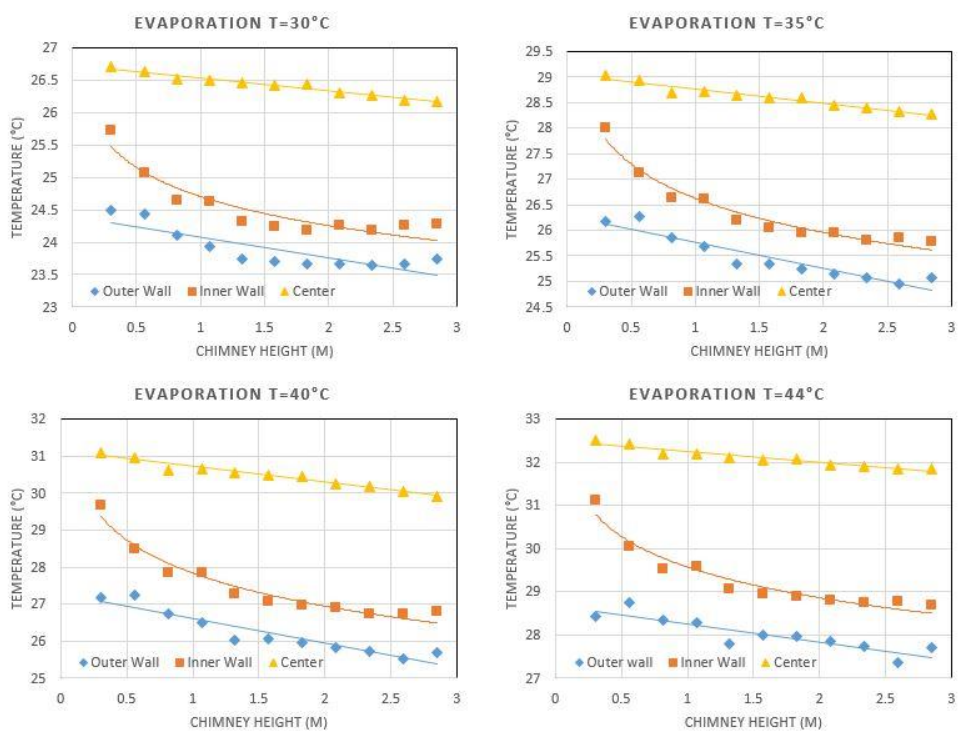

Fig. 6. Measured flow and wall temperatures in the cooling chimney with the water basin $1 \mathrm{~m} \times 1 \mathrm{~m}$
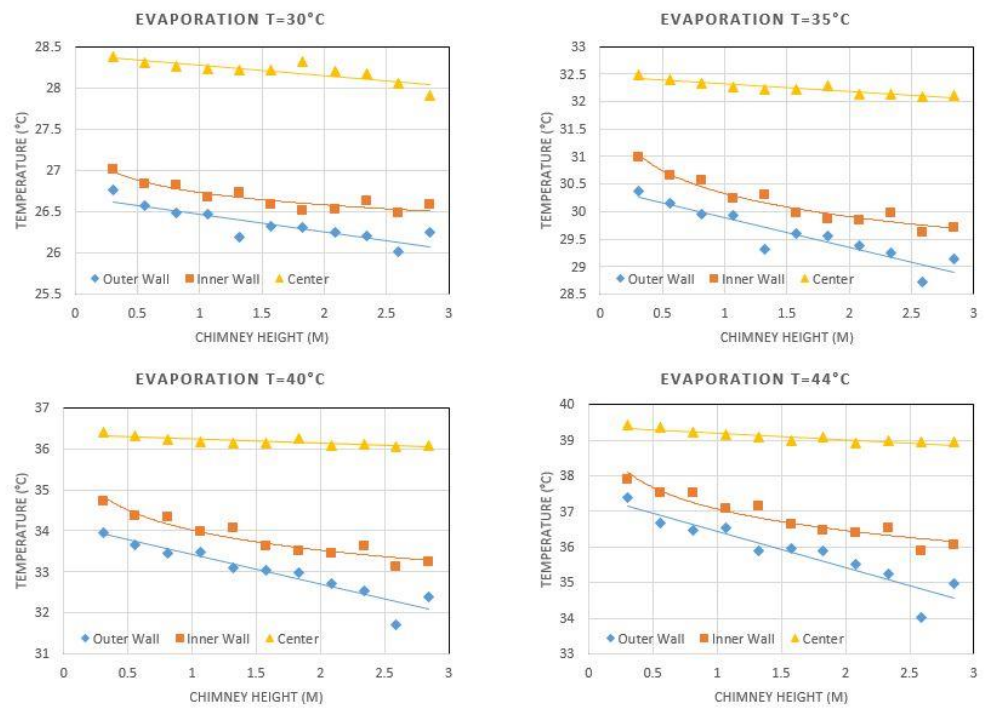

Fig. 7. Measured flow and wall temperatures in the cooling chimney with the water basin $2 m \times 2 m$

Shown in Fig. 6 and 7 are the measured temperatures along the height of the cooling chimney. Figure 6 is for the water basin of $1 m \times 1 m$, while Fig. 7 is for the case of water basin of $2 m \times 2 m$. The temperature difference between the center of the humid air, the inner wall and outer wall of the chimney are clearly observed. The temperature of the humid air in the center of the chimney decreases almost linearly, while the temperature of the inner and outer walls of the chimney decreases slightly faster at the entry length of the chimney. The temperature variation of the humid air from inlet to the outlet of the cooling chimney can reflects the water loss in the humid air due to the cooling and condensation of water vapor. The larger this temperature can decrease, the larger amount of water can be extracted 
from the humid air. In order to maximize this temperature decrease, longer chimney, cooler ambient air, or heat transfer enhancement measures will be required.

Experimental tests have been conducted with controlled water evaporation temperature (from $30^{\circ} \mathrm{C}$ to $50{ }^{\circ} \mathrm{C}$ ) and room temperature at $23 \pm 0.2^{\circ} \mathrm{C}$. For the water basin of $1 \mathrm{~m} \times 1 \mathrm{~m}$, the results of evaporation rate at different temperatures and different chimney open ratios are shown in Fig. 8. The measured data of evaporation rate versus the evaporation temperature shows a trend very similar to that shown in Fig. 4 for the ideal case. The evaporation rate of water is significantly affected by the airflow drawn into the water basin. When the chimney is fully open, the airflow rate is the maximum and therefore the water evaporation rate is also the highest compared to the cases that the chimney has smaller openings.

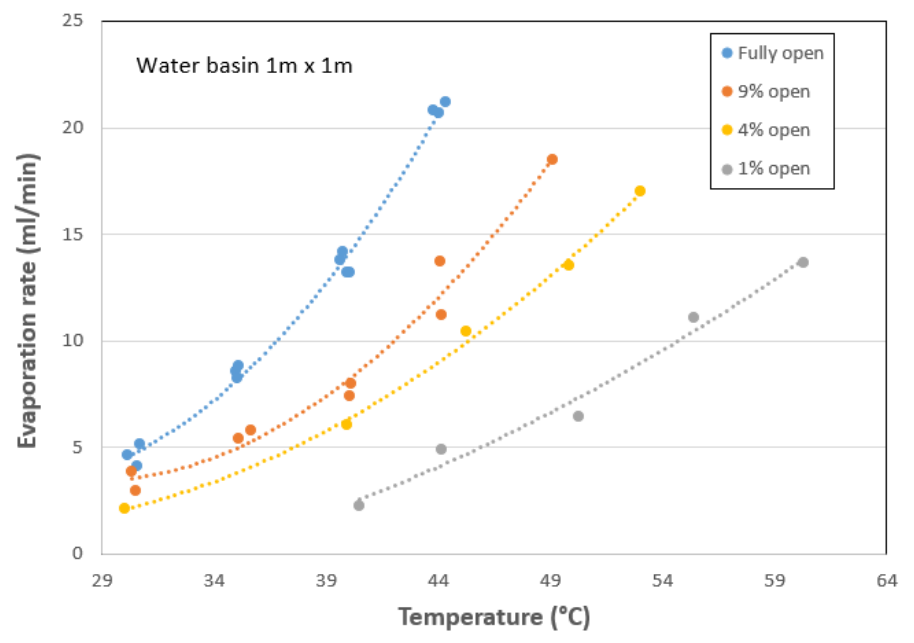

Fig. 8 Water evaporation rate under different airflow conditions due to the different opening of chimney exit

Under each case of opening of chimney exit (fully open or partially open), the water evaporation and condensation rates for the system with basin area of $1 \mathrm{~m} \times 1 \mathrm{~m}$ were compared in the measurements, and shown in Fig. 9 for three opening ratios of the exit of cooling chimney. Here the measured data of water condensation rate at $23^{\circ} \mathrm{C}$ versus the evaporation temperatures also shows a trend agreed very well with that shown in Fig. 4 for the ideal case. It was found that when the chimney has full open exit, there was no water condensed for clean water collection at tested basinwater temperatures from $30{ }^{\circ} \mathrm{C}$ to $45^{\circ} \mathrm{C}$. However, when the chimney was caped with openings of $9 \%$, $4 \%$, and $1 \%$, considerable amount of water condensation was observed and clean water was collected, as shown in Fig. 9 by the water evaporation rate and condensation rate at different temperatures. This phenomenon is related to the limitation of the mass transfer between the dry air and the water surface in the water basin. As Proven by the velocity measurement, the chimney with a full-open exit can draw a relatively large amount of airflow to the water basin. However, due to the small area in the basin $(1 \mathrm{~m} \times 1 \mathrm{~m})$, the dry air could not get fully humidified before it enters to the cooling chimney. In the meantime, the cooling in the chimney for the partly-humidified air cannot decrease the temperature sufficiently below the dew point, and therefore there is no condensate collected. On the other cases with smaller opening area at the exit of the chimney, smaller amount of airflow was drawn into the basin, and therefore, fully humidification for the dry air was made possible in the basin. When the fully humidified air is in the cooling chimney, any amount of temperature reduction by the cooling can make the saturated steam to condense into liquid water. Therefore, it is a very important point for the system design that the water basin must have a sufficiently large area so that mass transfer between dry air and water can sufficiently humidify the dry air to approach a relative humidity of 1.0. This requires the system design to avoid the case of a large and tall chimney while having a small water basin.

A sufficiently large water basin is the basic need to fully humidify the dry air at the water basin, however, too big of the area of the water basin can also waste the basin area. This is because that after the air reaches a humidity of 1.0, it will not take extra moisture with it. Therefore, an optimization of the water basin and the cooling chimney is needed, which has to be conducted through heat and mass transfer analysis. Obviously, the amount of dry air that can be drawn into the water basin depends on the height and diameter of the chimney as well as the temperature of the water in the basin. The coupled physics of chimney effect and heat mass transfer has to be studied through theoretical analysis.

Obviously, as long as the relative humidity of hot and humid air reaches 1.0, the temperature decrease in the humid air in the cooling chimney will definitely make the condensation of steam possible and thus liquid water can be 
harvested. However, the magnitude of the temperature decrease in the hot humid air will fully depends on the heat transfer performance of the chimney. Consequently, the condensation rate of water is fully determined by the cooling capacity of the cooling chimney. Heat transfer enhancement at the condensing surface inside of the chimney and the natural convection surface outside of the chimney should be promising measures for the improvement of the water harvest.

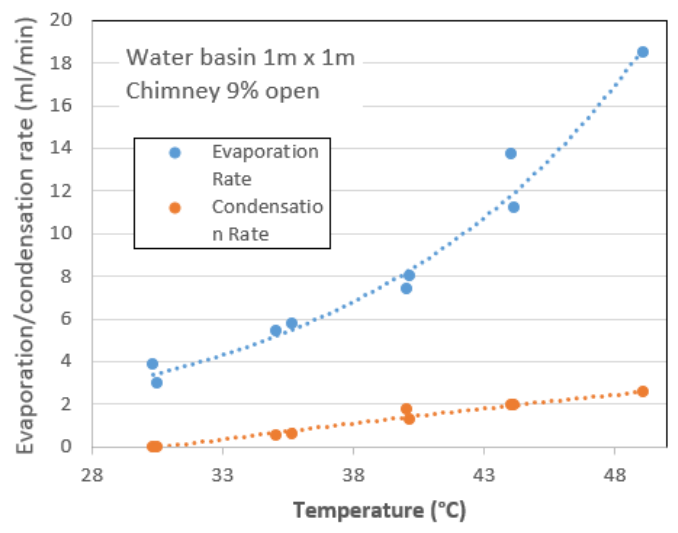

(a)

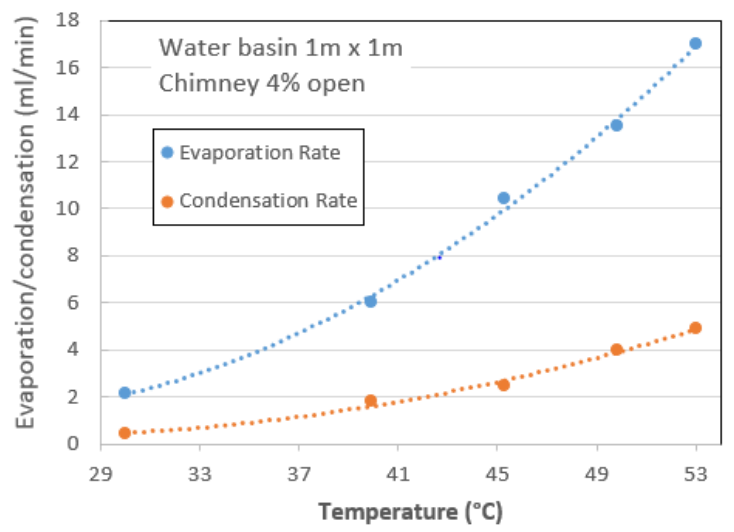

(b)

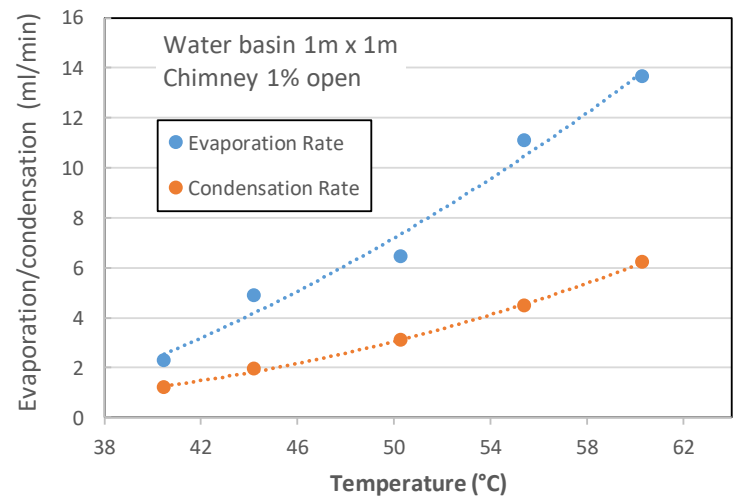

(c)

Fig. 9 Water evaporation and water condensation rates at different cases of openings of the exit of chimney 
Through the above discussions, it is concluded that the design of the current desalination system will consider two important factors, the first is the coupling of dimensions of the cooling chimney and the water basin for full humidification of the dry air drawn into the water basin to reach a relative humidity of 1.0. For the case of insufficient mass transfer or insufficient heat collection inside the water basin that makes less humidification to the air, control of the flow rate through controlling the opening of the exit of the chimney might be considered. Figure 10 shows the air flow rate going into the heat collection chamber when the chimney has different opening. Obviously, through the control of the exit opening rate of the chimney the air flow rate can be controlled. In further, this control of flow rate can make sure that the humid air at the inlet of the chimney can get a humidity of 1.0 so that the fully humidified air in the chimney can be cooled to obtain clean liquid water.

The second deterministic factor is about how to improve the ratio of water collection against water evaporation by enhancing the cooling capacity of the cooling chimney. Enhancement of the heat transfer inside and outside of the cooling chimney will be important.

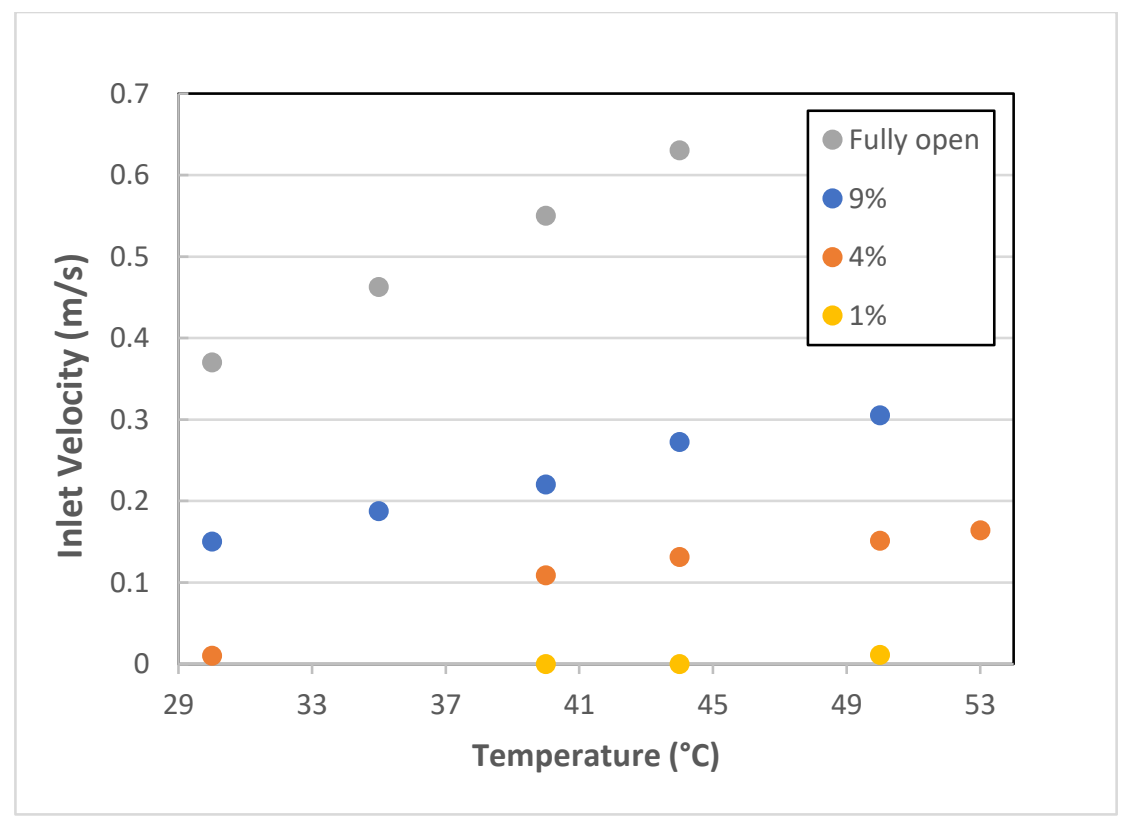

Fig. 10 Different amount of air flowing into the heat collection chamber through control of the exit opening ratio of the chimney

\section{Conclusion and future work}

This study presents a concept of a solar thermal energy driven desalination, with the objective of producing clean water and salts for valuable products with zero waste discharge, while having high energy efficiency and low cost. The system is composed of a solar collection chamber integrated with a water basin and a cooling chimney. As the first step to clearly understand the correlations between the solar collection chamber, the water basin, and the cooling chimney, some basic theoretical analysis has been conducted. At the same time, a lab-scale test system was constructed and experimental tests under controlled conditions of temperatures were carried out. The water evaporation rate in the water basin and water condensation from the moist air in the cooling chimney has been studied through theoretical analysis and experimental tests. The proof-of-concept was successful.

The experimentally measured data of water evaporation rate versus evaporation temperature showed a trend that agrees with the theoretically analyzed trend very well. The water condensation rate at room temperature of $23{ }^{\circ} \mathrm{C}$ in the cooling chimney shows a variation trend against the water evaporation temperature, which also agrees very well with that from the analytical results.

Experimental measurement to the temperatures of humid air, the inner and outer wall of the cooling chimney was conducted, which clearly demonstrated the temperature difference between the humid air and the cooling surface. These data will help the modeling work in the future for the flow and heat/mass transfer in the system.

Two critical design criteria were understood from the experimental results. First, the cooling chimney and the water basin must be designed to have a good coupling for their dimensions to make sure that the water surface area is 
sufficiently large for the dry air (due to chimney effect) to be fully humidified to a relative humidity of 1.0 . Under such a situation, water condensation in the cooling chimney will be ensured. Secondly, the cooling capacity of the cooling chimney is critical to the ratio of water condensation compared to the water evaporation.

Optimization of the entire system through further theoretical analysis for high efficiency is planned as the future work before real-world on-sun test is carried out.

\section{Acknowledgement}

Grateful acknowledgment is given to the University of Arizona Office of Tech Launch WEES funding for research on Water, Environmental, and Energy Solutions (WEES). Funding supports from Consortium for Arizona-Mexico Arid Environments - CAZMEX and Salt River Project are also appreciated and gratefully acknowledged.

\section{Reference}

[1] Elimelech, M. and W. A. Phillip (2011). "The Future of Seawater Desalination: Energy, Technology, and the Environment." Science 333(6043): 712-717.

[2] Li, C. N., Y. Goswami, et al. (2013). "Solar assisted sea water desalination: A review." Renewable \& Sustainable Energy Reviews 19: 136-163.

[3] J.H. Reif, W. Alhalabi, Solar-thermal powered desalination: Its significant challenges and potential, Renewable and Sustainable Energy Reviews, 48 (2015) 152-165.

[4] H. Sharon, K.S. Reddy, A review of solar energy driven desalination technologies, Renewable and Sustainable Energy Reviews, 41 (2015) 1080-1118.

[5] N. Ghaffour, J. Bundschuh, H. Mahmoudi, M.F.A. Goosen, Renewable energy-driven desalination technologies: A comprehensive review on challenges and potential applications of integrated systems, Desalination, 356 (2015) 94114.

[6] Turek, M. and P. Dydo (2003). "Hybrid membrane - thermal versus simple membrane systems." Desalination 157(1-3): 51-56.

[7] Cohen-Tanugi, David, Li-Chiang Lin, and Jeffrey C. Grossman. "Multilayer nanoporous graphene membranes for water desalination." Nano letters 16, no. 2 (2016): 1027-1033.

[8] Das, Rasel, Md Eaqub Ali, Sharifah Bee Abd Hamid, Seeram Ramakrishna, and Zaira Zaman Chowdhury. "Carbon nanotube membranes for water purification: a bright future in water desalination." Desalination 336 (2014): 97-109.

[9] Dong, Hang, Lin Zhao, Lin Zhang, Huanlin Chen, Congjie Gao, and WS Winston Ho. "High-flux reverse osmosis membranes incorporated with $\mathrm{NaY}$ zeolite nanoparticles for brackish water desalination." Journal of Membrane Science476 (2015): 373-383.

[10] Emadzadeh, D., W. J. Lau, M. Rahbari-Sisakht, A. Daneshfar, M. Ghanbari, A. Mayahi, T. Matsuura, and A. F. Ismail. "A novel thin film nanocomposite reverse osmosis membrane with superior anti-organic fouling affinity for water desalination." Desalination 368 (2015): 106-113.

[11] Palenzuela, P., D. Alarcon, et al. (2013). "Parametric equations for the variables of a steady-state model of a multi-effect desalination plant." Desalination and Water Treatment 51(4-6): 1229-1241.

[12] H. EI-Dessouky, H. Ettouney (Eds.), "Fundamentals of Salt Water Desalination." Elsevier Science BV, Amsterdam, 2002.

[13] Li, C. N., D. Y. Goswami, et al. (2012). "A new combined power and desalination system driven by low grade heat for concentrated brine." Energy 46(1): 582-595.

[14] Fernandez-Lopez, C., A. Viedma, et al. (2009). "Seawater integrated desalination plant without brine discharge and powered by renewable energy systems." Desalination 235(1-3): 179-198.

[15] W. Omar, J. Chen, J. Ulrich, Reduction of seawater scale forming potential using the fluidized bed crystallization technology, Desalination 250 (2010) 95-100.

[16] Zhai, Y., Ma, Y., David, S. N., Zhao, D., Lou, R., Tan, G., Yang, R. \& Yin, X. (2017). Scalable manufactured randomized glass-polymer hybrid metamaterial for daytime radiative cooling. Science, 355(6329), 1062-1066.

\section{*Appendix}

Eq. (6), $\rho_{\text {moist-air }}=\rho_{\text {dry-air }}(1+x) /\left(1+x \frac{R_{\text {water }}}{R_{\text {air }}}\right)$ is derived through the following steps.

For dry air with no humidification, there is $\rho_{\text {dry-air }}=P_{\text {total }} /\left(R_{\text {air }} T\right)$. 
For humid air, there is $\rho_{\text {moist-air }}=P_{\text {total }} /\left(R_{\text {moist-air }} T\right)$.

Divide Eq. (A2) by Eq. (A1), there is: $\rho_{\text {moist-air }}=\rho_{\text {dry-air }} R_{\text {air }} / R_{\text {moist-air }}$

For the humid air, ideal gas law gives $P_{\text {total }} V=\left(m_{\text {air }}+x m_{\text {air }}\right) R_{\text {moist-air }} T=m_{\text {air }} R_{\text {air }} T+x m_{\text {air }} R_{\text {water }} T$ (A4)

Find $R_{\text {moist-air }}$ from Eq. (A4), and then bring it to Eq. (A3), one can get Eq. (6). 